Article

\title{
Operative Monographies: Development of a New Tool for the Effective Management of Landslide Risks
}

\author{
Daniele Giordan ${ }^{1} \oplus$, Martina Cignetti ${ }^{1, *}$, Aleksandra Wrzesniak ${ }^{1}$, Paolo Allasia ${ }^{1}$ and \\ Davide Bertolo $^{2}$ \\ 1 National Research Council of Italy, Research Institute for Geo-Hydrological Protection (CNR IRPI), \\ Torino 10135, Italy; daniele.giordan@irpi.cnr.it (D.G.); aleksandra.wrzesniak@irpi.cnr.it (A.W.); \\ paolo.allasia@irpi.cnr.it (P.A.) \\ 2 Strutture Attività Geologiche, Regione Autonoma Valle d'Aosta 2, Quart 11020, Italy; \\ davide.bertolo@regione.vda.it \\ * Correspondence: martina.cignetti@irpi.cnr.it; Tel.: +39-011-3977-831
}

Received: 8 October 2018; Accepted: 8 December 2018; Published: 14 December 2018

\begin{abstract}
Active landslide risk assessment and management are primarily based on the availability of dedicated studies and monitoring activities. The establishment of decision support for the efficient management of active landslides threatening urban areas is a worthwhile contribution. Nowadays, consistent information about major landslide hazards is obtained through an interdisciplinary approach, consisting of field survey data and long-time monitoring, with the creation of a high populated dataset. Nevertheless, the large number and variety of acquired data can generate some criticalities in their management. Data fragmentation and a missing standard format of the data should represent a serious hitch in landslide hazard management. A good organization in a standard format can be a good operative solution. Based on standardized approaches such as the ICAO (International Civil Aviation Organization), we developed a standard document called operative monography. This document summarizes all available information by organizing monitoring data and identifying possible lacks. We tested this approach in the Aosta Valley Region (NW Italy) on five different slow moving landslides monitored for twenty years. The critical analysis of the available dataset modifies a simple sequence of information in a more complex document, adoptable by local and national authorities for a more effective management of active landslides.
\end{abstract}

Keywords: landslide monitoring; dataset management; decision-maker support; Aosta Valley Region

\section{Introduction}

Landslides are one of the most common natural disaster throughout the world [1,2]. Different authors have studied their impact on population and infrastructure [3-5], which also pointed out the costs and effects on society.

The definition of the impact of landslides is usually performed through dedicated risk management procedures [6-9]. These operations are multi-component decision-making processes aimed at reducing the impact of landslides on territories and infrastructure, and creating mitigation strategies. This entails a compound framework of various actions such as (i) land use planning, (ii) engineering intervention, (iii) monitoring and warning system [10].

In Italy, landslides constitute a big issue, affecting about $6.9 \%$ of the regional territory [11], often causing causalities and economic losses [12]. Landslide risk management requires participation at various levels by national, regional, and municipal authorities, often with the support to decision makers of the scientific community. It is notable that, in the case of large active phenomena involving urban areas, infrastructure, and population, the National Civil Protection intervention is required. 
A broad overview of those phenomena becomes an essential guidance for any decision and evaluation in landslide risk management [13], and land use planning establishment [14,15].

The underlying element in landslide risk management consists of landslide inventory and associated dataset. In Italy, the Italian Landslide Inventory, named IFFI [11], involves national, regional, and local institutions. This inventory has a homogeneous and integrated collection mode of landslide data over the entire national territory. Specifically, for each inventoried phenomenon, IFFI produced a "Landslide Data Sheet" [16], which collects the qualitative and quantitative parameters of the considered phenomenon. The structure of this project is a GIS group of layers and an associated database. From that project, regions and local authorities derived similar products like: (i) "Piedmont Landslides Information System" (SiFraP) [17], (ii) "Catasto Dissesti" a landslide registry of the Aosta Valley Region [18], (iii) "Carta Inventario delle Frane" a map inventory of the Emilia-Romagna Region [19], (iv) the Tuscany inventory [20], (v) the "AVI project" tested on the Umbria and Marche Regions [21].

Inventories and datasets are cornerstones in support investigations, by providing updated information on where and when landslides occurred. In recent years, innovative approaches have provided an important step forward by integrating the existing inventory with other resources derived from technical community [22], or benefit from application of semantic engine to scan news available on internet [23]. Alongside, the scientific community emphasized the importance of correct management of data, their clear representation and dissemination in the field of landslide monitoring [24-26].

Taking into account active landslides, consistent information about each single unstable area may occur. Indeed, the high vulnerability of those cases required an in-depth characterization of the hazardous landslides. For more complex and hazardous situations, simple identification and mapping of phenomena is not enough. In these cases, regional and local authorities commonly carry out or order landslide investigation studies, concerning the exploitation of the internal structure of the landslide, its type of movement, state of activity, history, triggers, etc. These studies aimed to evaluate the current hazard level can be supported also by monitoring systems that are fundamental for the definition of the evolution of the slope instability. Due to the kinematic evolution of active landslides, these analyses can go on for many years, also by repeating, in order to provide advancements in the interpretation of landslide behavior. It should be noted that the repetition and the progressive update of the studies from the past generates a flux of additional information that is hard to handle.

In fact, this sequence of information, based on a dataset that can evolve during the time, can produce differences in the geological model, in landslide geometry definition, or in the evaluation of the level of danger, and/or the identification of elements at risk according to landslide activity. The accumulation of new information and the possible definition of models that can differ from precedents should be carefully considered and managed in order to avoid the presence of documents or studies with conflicting conclusions.

As mentioned before, the study of active landslides frequently requires the use of several monitoring systems, able to support the development of the geological model, control landslide evolution, and if necessary, to be exploited as an early warning system in case of collapse of the landslide. Monitoring can be performed using traditional in situ system as: (i) Global Navigation Satellite System (GNSS) [27,28]; (ii) Robotized Total Station (RTS) [29]; (iii) inclinometer and piezometer boreholes [30]. In addition, can be used remote sensing techniques, like: (i) Ground Based SAR [31]; (ii) satellite SAR interferometry [32-34]; (iii) Light Detection and Ranging LiDAR [35,36].

By considering active landslides, on one hand, the scientific community proposed effective methodologies and integrated services for design, evaluate and manage landslide risk $[20,24,26]$. Moreover, many researches discussed landslide monitoring networks [36], landslide risk assessment [7], and early warning system application $[37,38]$. On the other hand, policy-makers entrusted private agency to investigate and collect information on landslide behavior and their evolution over time. If we consider the amount of data that could be generated on a single landslide by: (i) Data collected in landslide inventories; (ii) thematic studies (e.g., technical reports, maps and technical annexes) of the 
unstable area; and (iii) the associated monitoring activities, we can realize that one of the future critical issue will be the correct management of available information. A "Risk management guidelines" document has been proposed by AGS [9] in Australia, a "Code for practices for landslide hazard and land use planning" [6] is described by [8] in Switzerland, highlighting the need of the regional authorities for a standardized approach for the risk mitigation. However, a tool for handling those multi-source and varied data, specifically for active landslides involving urban and/or elements at risk, focused on the organization and standardization of consistent information derived from the assessment of an unstable area, is actually missing. After many years in which the scientific community has dedicated their efforts to the acquisition of information about landslides, nowadays one of the most important challenges is the correct use and management of available data and studies. Often, the exclusive use of web-GIS solutions is not enough, because several web-GIS are simple repositories where thematic studies and monitoring data are stored and available. The difference between the availability of information and their "usable" version has been called usable science and its importance has been pointed out in many fields like, for example, climate change [39-41]. The main aspect of this approach is that scientific information have to be useful and usable [41] and that decision makers must perceive information "not only credible, but also salient and legitimate" [42]. In landslide study, the correct organization of data requires a document where data are analyzed and commented, and the state of the art of what we know and what do not yet know of the studied phenomena is outlined.

This work presents a methodology developed to provide a guidance for an effective management of large and complex data regarding active landslide risk management. In particular, we considered landslides that have a long monitoring and studying history due to the possibility that a critical evolution could cause a partial or total collapse. To collect and organize all available information, we developed a document named Operative Monography (OM) that provides an overview of the available data about a certain unstable slope. OM have a standard organization of sections and contents that has been defined considering other similar documents developed for others purposes. In particular, we considered the organization model defined by the International Civil Aviation Organization's (ICAO) Operative Manual structure. In the civil aviation field, the ICAO sustained strong efforts to achieve a clear and detailed definition of how the manual of operation of a private company that manage aircraft should be organized and managed. Starting from this example, we tried to follow the same approach for the definition of a document model that can be adopted as a standard model in the field of landslide study and monitoring.

The OM could be a useful tool for public safety authorities, which supplies always updated brief overview of each hazardous phenomenon located in the areas of high vulnerability. The document has been designed to collect available data to support decision makers combining a rigorous scientific method with a usable science approach.

We developed and tested OMs in the Aosta Valley Region (NW Italy). This mountainous region is affected by more than 5218 slope instabilities, and six of them are highly hazardous. The Regional Geological Survey has studied these six large complex landslides since many years, collecting various thematic studies (e.g., geological, geomorphological, hydrological, risk scenario). Moreover, a regional near real time monitoring network has been implemented in order to control the evolution of the most critical landslides. The development of OMs starts with analysis of the large amount of data of the regional archive, in order to assess all the information acquired on the unstable area and outline eventual data fragmentation, missing data, or other relevant data that should represent a strong problem in effective landslide hazard management. In this paper, we discuss the organization of data archive, focusing on the five landslides of Bosmatto, Becca di Nona, Chervaz, Citrin, and Vollein, all located across the regional territory. All these landslides are characterized by a long and slow evolution, emphasized by a large amount of data and information, associated with long-time ground deformation time series derived from a near real-time monitoring network data acquisition, acquired in the last twenty years. We analyzed both the data of the existing monitoring systems, and all the data collected over time (e.g., technical reports, thematic maps, technical annexes). 
In this work, we operated as follows: (i) We analyzed the private regional archive; (ii) we implemented the OM standard structure; and (iii) we redacted the OMs. An example of OM is presented and discussed. The OM structure is divided into four main sections relative to: (1) General information about the unstable phenomenon, (2) previous data analysis and organization, (3) ground deformation time series analysis, and (4) synthesis of the actual knowledge of the slope instability and eventual proposal of integration with new studies or monitoring activities.

Proposed OMs can be considered a possible standard in the management of studied landslides and they also represent a pilot test suitable for further investigations in other geographic and physiographic contexts and can be considered a useful instrument to support the reduction of effects of natural hazards on human activities.

\section{Landslides of Aosta Valley Region}

The Aosta Valley is a small region $\left(3200 \mathrm{~km}^{2}\right)$, located in an alpine mountainous territory in northwestern Italy. The elevation ranges from $312 \mathrm{~m}$ (Pont Saint Martin) to $4810 \mathrm{~m}$ a.s.l. (Monte Bianco peak), and more than half of its territory has an elevation above $2000 \mathrm{~m}$ a.s.1.. This territory reveals a notable exposure to landslide hazards (Figure 1), in which geo-structural setting and geomorphological history strictly influence landslides occurrence.

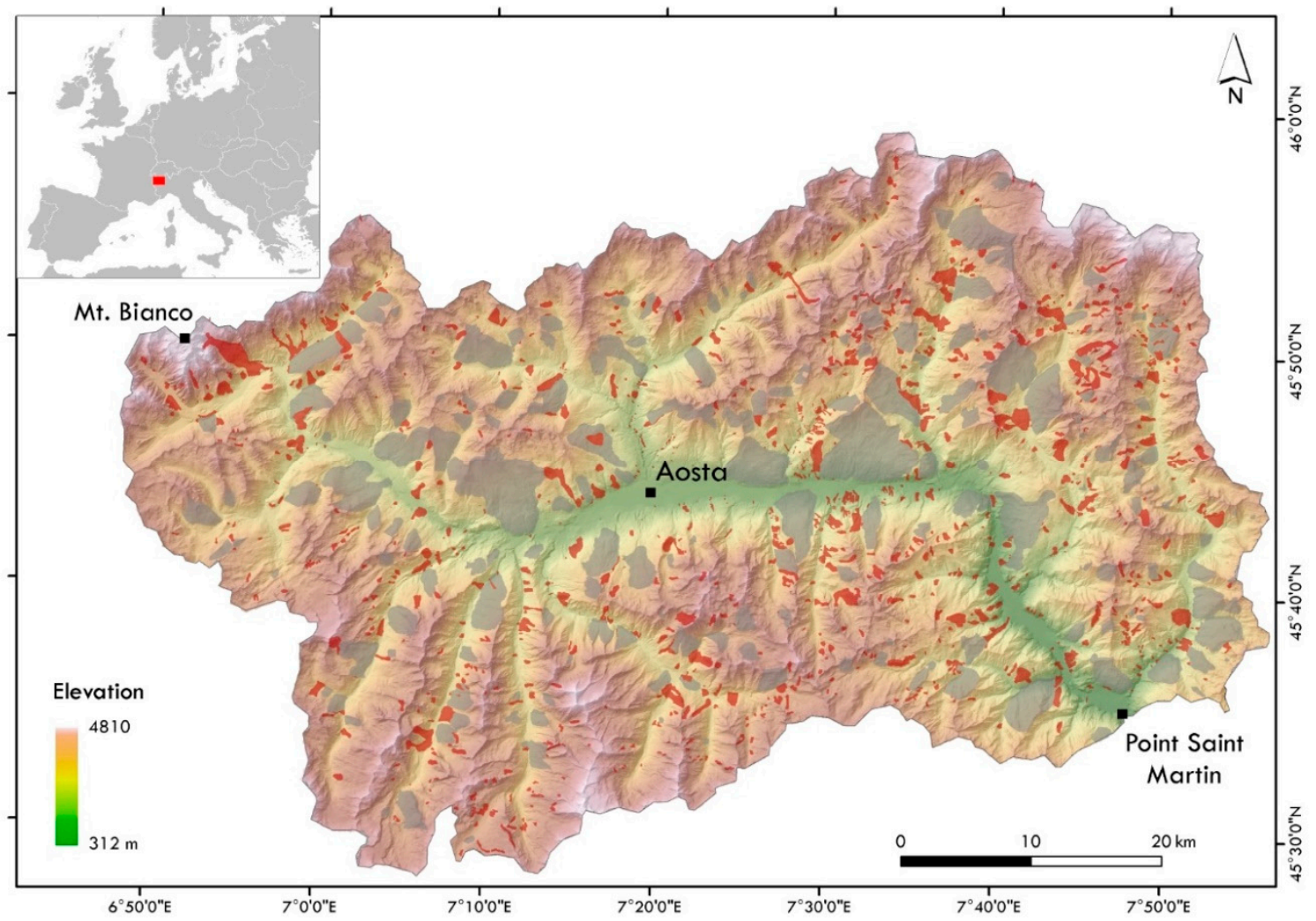

Figure 1. Landslides map distribution of the Aosta Valley Region (northwestern Italy): Grey polygons correspond to the Deep-seated Gravitational Slope Deformations, red ones to the landslides inventoried in the IFFI project (IFFI - Italian Landslide Inventory) Catalogue [11].

The geological setting of the Aosta Valley region is the outcome of the African and European plates collision. This region passes through the Europe-vergent Austroalpine-Penninic structural domains of the Western Alps $[43,44]$. A complete section of the orogenic prisms outcrops, crossing the complex pile of nappes constitute by the tectonic-metamorphic units represented by: (i) The Austroalpine domain, (ii) the ophiolitic Piedmont zone, and (iii) the Pennidic domain. The alpine relief in this section is characterized by a long-term tectonic activity and by a neo-tectonic dislocation system represented by 
the Aosta-Ranzola fault [45]. This structural-geological context deeply influenced the relief evolution and the slope dynamics [46].

Morphologically, glacial morphodynamic prevails and influences the ancient and the actual slope setting, principally due to the debuttressing caused by glacier retreat. Watercourses dynamic superimposes the glacial landforms, generating fluvial deposits and forming alluvial and detrital fans set by debris-flow phenomena [47].

Based on a regional landslide inventory, more than $17 \%$ of this region is affected by gravitational phenomena [48]. Regional landslide inventory includes large amount of phenomena of various types and sizes. It is periodically updated by regional authorities [18] and it currently comprises 12,589 phenomena. Such phenomena include shallow landslides (e.g., debris flow, planar and rotational slide), rock fall, and large slope instabilities. Complex landslides and Deep-seated Gravitational Slope Deformations (DsGSDs) are respectively the $9 \%$ and the $5.4 \%$ of the total amount of regional landslides [49].

Considering the large number of inventoried phenomena in Aosta Valley Region, only some of them are active and directly threaten urbanized areas and infrastructure. It is worth to note that the level of risk can increase according to the magnitude of the landslide and the vulnerability and exposition of elements at risk. Therefore, regional authorities operate by a discernment of active landslides based on their impact on infrastructure and population. They have managed the risk related to these phenomena by specific measures to define prevention strategies and useful land use planning. These measures include the acquisition of all the basic information and knowledge for each unstable phenomena, based on an interdisciplinary approach, concerning a multi-scale and temporal investigation.

In Aosta Valley, there are about thirty active landslides monitored in the past or currently measured by different monitoring networks that in some cases can also involve urbanized areas and/or infrastructure. Among those cases, in the paper we present the application of OM on five phenomena studied for many years and are currently monitored by near real time monitoring systems. They correspond to the landslides of: (1) Bosmatto, (2) Chervaz, (3) Vollein, (4) Becca di Nona, and (5) Citrin (Figure 2). This reduced group of phenomena consists of active large complex landslides that could seriously threaten urban areas. Therefore, they are studied and investigated by in-depth analysis (e.g., geological-geomorphological and structural surveys, hydrological and hydrogeological survey, risk scenario) Table 1 reports location, type of phenomenon, and volume for each considered landslides.

All considered landslides are monitored by remote near-real time systems (with continuous measurements) and by temporary systems (with periodical measurements) because of the possibility that the displacement rate can increase and a total or partial collapse can occur. Near real-time monitoring systems automatically measures the superficial displacement by means of Robotized Total Station - RTS (Vollein, Chervaz), Global Positioning System receivers - GPS (Bosmatto, Chervaz, Becca di Nona), and extensometers (Bosmatto, Becca di Nona, Citrin). Additionally, in the case of Chervaz, inclinometric columns [50] were installed to measure deep-seated displacement. For all these sites, the superficial displacement is also manually measured by means of GPS receivers, with periodical campaigns. 

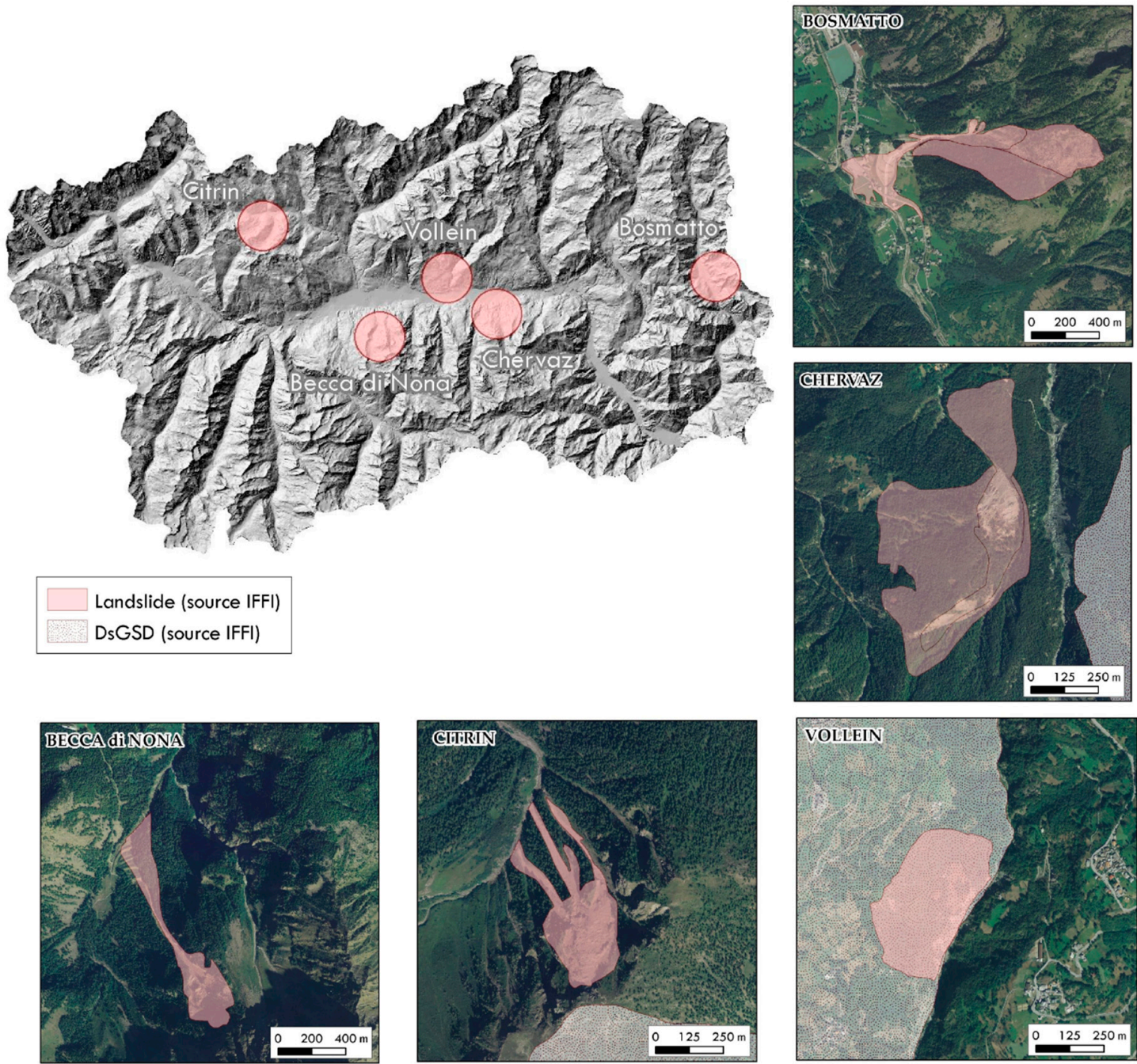

Figure 2. Location of the five complex active landslides of the Aosta Valley Region. Presented polygons came from IFFI Project [11]

Table 1. Summary of the landslide monitoring network system of the Aosta Valley Region.

\begin{tabular}{cccc}
\hline Landslide & Location & Type & $\begin{array}{c}\text { Volume } \\
\mathbf{( 1 0}^{\mathbf{6}} \mathbf{~ m}^{\mathbf{3}} \mathbf{)}\end{array}$ \\
\hline Bosmatto & Gressoney Saint-Jean, Lys Valley & Complex landslide evolving in debris flow & 2 \\
Chervaz & Chambave-Fenis municipalities & Complex landslide & 1.2 \\
Vollein & Quart municipality & Complex landslide evolving in & 1.5 \\
Becca di Nona & Chervansod-Pollein municipalities & Complex landslide prevalently slide & 1.9 \\
Citrin & Saint-Rhêmy-en-Bosses municipality & Complex landslide & 1.5 \\
\hline
\end{tabular}

\section{Methods}

The development of the OM, based on the Aosta Valley Region case study, is structured in two principal steps: (i) Previous data and available material acquisition, and (ii) OM structure description. The OM structure is divided in sections about: (i) General information about unstable area; (ii) previous data analysis and organization; (iii) ground deformation time series analysis; and (iv) synthesis and eventual improvement proposals. 


\subsection{Back Data and Available Material Acquisition}

Geological Survey of the Aosta Valley Region collected a large amount of various kind of data in the last decades, for the six most critical gravitational phenomena of Bosmatto, Becca di Nona, Chervaz, Citrin, Vollein, and Mont de la Saxe. In the case of a partial or total collapse of the instable mass, the vulnerability of elements at risk can be very high because inhabited areas are involved. The first five phenomena have a long-time slow evolution often linked to activation (or reactivation) occurring during a rainfall event, described extensively by a large number of technical studies and especially by long-time ground deformation series acquired by a near real-time monitoring network. In some cases, the monitoring even acquired for twenty years. Instead, for the Mont the la Saxe case study, the near real-time monitoring network started from 2009 [24].

Focusing on these slow evolution landslides, we examined the regional archive that constitutes the main source of information necessary to create and compile the OM. This archive mainly consists of scientific and technical reports, thematic maps, technical annexes, and internal reports, acquired in the last twenty years. Based on the analysis of available data, we extracted eight common principal categories:

- Geological-Geomorphological survey (GeoGeomS);

- Geological map (GeoM);

- Geomorphological map (GeomM);

- $\quad$ Structural Survey (StrM);

- Geological Profile (GeoP);

- Hydrological/Hydrogeological (Hyd/Hydg);

- Risk scenarios and Spatial prediction model (Rsk/Sc);

- Monitoring Network report (MonNet).

Those categories correspond to the main topics widely investigated in the field of landslide risk assessment and management. In some cases, ancillary data are reported, including e.g., geophysical surveys, electric tomography surveys, technical reports for monitoring network installation, and engineering interventions.

The Geological Survey of Aosta Valley often entrusted landslide analysis and data elaboration to private and public agencies, which use different ways to represent the same typology of data or that could reach different conclusions according to the dataset available at the moment of the study. Those activities generated a multiplicity of technical reports prepared in different ways about the same topic (e.g., structural-geology, profiles and maps, risk scenarios). During the analysis of the available data, we found a great amount of available information that have been collected by the regional authority. In some cases, the usual approach, which is the redaction of thematic studies or annual reports, can produce a stratification of information. Considering long time series, it is possible to find some changes in the structure of reports that describe the same dataset. These changes could have limited the possible reconstruction of the whole time series. Thanks to the great effort of the region authority in the study of these phenomena, we had the opportunity to perform an in-depth analysis of the main critical points related to the availability of long monitoring time series and many detailed studies. These time series, acquired in a period characterized by fast technological improvements, suffered the fallout of these technological changes and the lack of a standardized modality of acquisition and description of the datasets.

\subsection{Operative Monography Structure}

To homogenize and integrate the available landslide data, we implemented a methodology for the redaction of OMs. OM is a document in which all the information and data acquired over time are organized and summarized in a standardized format.

As mentioned before, we considered the guidelines of Operation Manual proposed by Civil Aviation Organization (ICAO—document 9376) to define the structure of OM. This Operation Manual 
describes how an aviation company should organize internal procedures in order to manage all the activities related to the safe use of civil aircrafts. ICAO document defines explicitly the necessary chapters and their contents. In the case when information for a particular chapter are not available, the chapter should be left empty to satisfy required structure. Following the described approach, we divided the structure of landslide OM into four sections: (i) General information about unstable area; (ii) previous data analysis and organization; (iii) ground deformation time series analysis; and (iv) synthesis and eventual proposal.

As described in the ICAO, the sequence of the sections is a fundamental characteristic of operational documents. This guideline should be respected for each case study. Thanks to this, the identification of missing elements or the consultation of existing ones is facilitated. In fact, in OMs, some sections may remain empty when the specific data is missing. Such an approach emphasizes the possible lack of information. In the following sections, the OM subdivisions are presented and described.

\subsubsection{OM-General Information}

The first section of the OM refers to basic information of the considered landslide. In detail, this section briefly reports landslide geographical location, type, and state of activity. Additionally, this section provides short description of morphometric parameters, geo-lithological, geomorphological and structural settings, and land use setting.

When landslide interferes with elements at risk (e.g., linear infrastructure, road, path) a separate item is planned. This possible interference with human activities or infrastructure is, of course, a fundamental issue that should be carefully described. In this section, the results of hazard assessment and $\backslash$ or landslide collapse simulations are also presented.

\subsubsection{OM-Previous Data Analysis}

In this section, an in-depth analyses of the existing datasets are performed. These sets of historical information about unstable areas originates from diverse sources: Data stored in national and regional inventories, technical reports and studies associated with monitoring networks data (usually performed by private agencies), and Geological Survey's internal reports.

We developed a reiterative pattern, reporting only fundamental information of defined categories. We listed basic information like private agency name, month/year of delivery, topics covered, etc. to classify the numerous technical reports, field surveys and associated thematic maps, and technical annexes. All information are reported in tabular format. Due to this operation, the presence or absence of technical documents and information relative to specific topic can be quickly verified. The important difference between an ordinary copy of available material and OM is that, in the second case, only fundamental information are described. The objective of $\mathrm{OM}$ is not the simple copy of available material, but their brief summary and their source determination. In this way, readers who have to consult the OM can also recover the original position of reported information if detailed analyses of the original documents are necessary. We summarized the collected information in three main topics: (i) Geological-geomorphological setting, structural analysis, and hydrological-hydrogeological aspects, (ii) risk scenarios and landslide spatial prediction models, and (iii) monitoring network system. Representative images, photos, maps, and tables can accompany the brief description.

\subsubsection{OM-Ground Deformation Time Series Analysis}

As mentioned before, the study of active landslides, which may require the use of OMs is usually supported by monitoring systems. The acquisition and processing of monitoring data can be done by national and regional authorities or entrusted to private agencies. If we consider long time series, the lack of a specific guideline for the acquisition and elaboration of acquired data can hamper the data representation continuity. If several companies performed the acquisition of the same data in different moments, the risk that the same data were presented in different ways is very high. For long-term 
landslide evolution, the presence of discontinuities in the organization and elaboration of the same monitoring sequence can reduce the benefits coming from a detailed analysis and comparison of data, in particular if raw data were not included in the report. Therefore, the standardization of acquisition and presentation of information, and the availability of raw data is fundamental.

In this OM section, the collected monitoring datasets from monitoring network and /or near-real time system of an unstable area are re-organized and pre-analyzed. We used MATLAB ${ }^{\circledR}$ [51] environment to manage monitoring data. First, raw data were filtered and validated by removing inconsistent data, noisy measurements, and spikes. Then, eventual gaps are closed using the best approach that depends on the characteristics of the dataset. Later, specific mathematical functions were applied to these pre-elaborated data sets (e.g., moving average, local regression using weighted linear least squares and a 1st degree polynomial model or its robust version that assigns lower weight to outliers in the regression), in order to obtain an overall representation of landslide behavior.

The measured physical quantity depends on the technical specification of the instrumentation used. For example, RTS, GPS receivers, or extensometers can provide the same physical parameter but the dataset of each instrument has a different organization and different data. For example, in the case of GPS receivers, the measured quantity is a displacement in three-dimensional space $(x, y$, and $z)$; for RTS it is vertical and horizontal angles and line-of-sight distance. However, we generated, for both cases, the time-series plot of the same variable, i.e. planimetric and altimetric displacement, which is the most convenient and representative way to describe landslide behavior. Moreover, the smoothing techniques were tested in order to adapt the suitable type to each dataset. In this way, especially for long-time plots, the evidences of seasonal accelerations or other patterns were not omitted. Such complete time series are used to synthesize the overall landslide behavior over time.

As described in the ICAO operational manual and in OM, the document should be updated every time when there is an important event and/or information. This means that continuous update of information according to the availability of new monitoring data is fundamental. According to the landslide risk level, the time series should be updated with a certain frequency that can be, for example, every 6 months or every year.

\subsubsection{OM-Synthesis and Final Proposals}

The final part of the OM corresponds to a brief synthesis of the general framework of the analyzed phenomenon. Here, the eventual strengths and the observed lacks and/or inconsistencies were highlighted.

The goals of this section are: (i) To provide a short summary as comprehensive as possible of the available data, (ii) highlight possible missing data or information, and (iii) provide several suggestion for definition of the new activities aimed to improve the comprehension of the studied landslides. Here a concise comment of the OM contents points out also possible weaknesses, on which should be oriented future interventions and actions. In the proposed structure of OM, this final section is important because it makes the difference between a simple resume of available information and an operative document that is also aimed to provide indications for future analysis and actions.

\section{Operative Monographies Application in Aosta Valley Case Studies-Results}

We applied our methodology to the data of some slow moving complex landslides of Aosta Valley region, providing OMs to the Regional Geological Survey. For example, in Annex 1 (Supplementary material), we report a simplified version of one of the case studies, the Bosmatto landslide, in order to show the general OM structure.

The Bosmatto case study is located in Gressoney-Saint-Jean municipality, Lys Valley, within the Letzè catchment. Based upon the geological and geomorphological studies, two old landslides have been recognized on the left side of the basin. In connection with the old landslide named "paleofrana 1" (vd. Annex 1), a complex landslide, evolving in an impressive debris flow, affected the Letzè basin during October 2000, involving the alluvial fan [52]. For the Bosmatto landslide, a thickness of about 
$25 \mathrm{~m}$ was estimated, with a computed volume of $2,000,000 \mathrm{~m}^{3}$. The landslide is monitored by a manual GPS network since 1997, and by automated GPS since 2002, and by extensometers for a limited period from summer 2006 to autumn 2010. Moreover, a GBInSAR monitoring has been performed from October 2016 to November 2017. The long-time series allow synthesizing the overall landslide behavior over time, displaying an independence from the rain and snow regime.

On the right side of the Letzè basin, another phenomenon occurred during the summer 2002. Field survey, also associated with seismic analysis, reveals that this phenomenon, the Stadelte landslide, has variable thickness from $5 \mathrm{~m}$ to $20 \mathrm{~m}$. From the GSP measurements analysis, a cross-correlation from snowmelt and seasonal reactivation has been assumed. In the Bosmatto OM first section, the general information of this landslide are reported, with a one-page summary with a brief description of the type of landslide, state of activity, geological and geomorphological setting of the unstable area (Annex 1, Section 1). This provides sort of "register tab" of the considered phenomenon.

In the following section "Previous works analysis", the examination of the available data reveals 22 documents, which include technical reports, maps and technical annexes, drafted by four private agencies. A summary of the topic of the document and the agencies that drafted it has been reported in tabular format (Annex 1, Section 2, Table 1), following the main categories occurred.

Of all this large amount of data, the key information have been reported in the OM in a synthetic format, associated with the meaningful maps and/or profile of the analyzed landslide (Annex 1, Section 2). By this way, we collect all the geological, geomorphological and structural information, the monitoring network status, and the eventual risk scenarios, describing the state of knowledge, in order to define a reference model for landslide behavior assessment.

The high number of studies and technical reports, associated with maps and geological profile, recurs also in the other case studies (Figure 3).

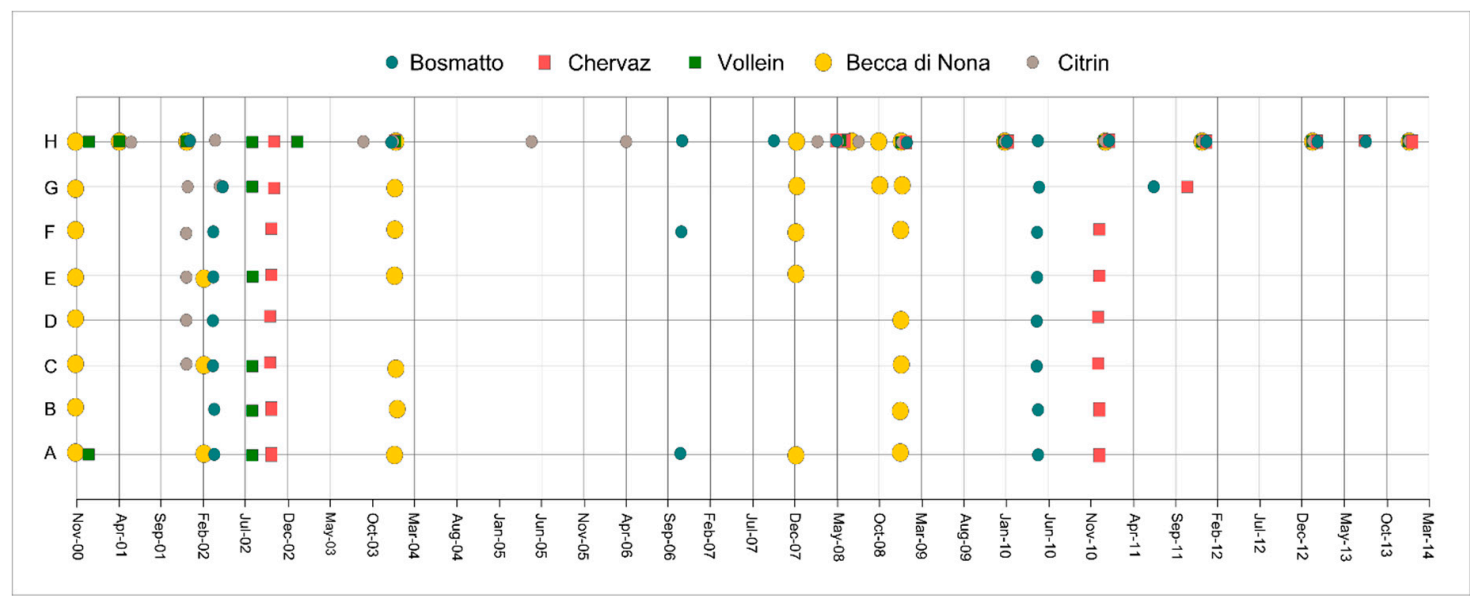

Figure 3. Time distribution of the data available for each considered landslide, divided in the eight recognized topics: (A) GeoGeomS; (B) GeoM; (C) GeomM; (D) SrtM; (E) GeoP; (F) Hyd/Hydg; (G) Rsk/Sc; and (H) MonNet.

Figure 4 reports the total number of available information, split into the eight principal categories and divided for each case study. The graph highlights the constant presence on the "MonNet" category for all the five landslides. Whereas, some variable are missing, as "StrM" and "Hyd/Hydg" for the Vollein case. Moreover, we can observe that, in the Chervaz, Becca di Nona and Bosmatto case studies, there are more than two geological-geomorphological survey reports, as well as for the risk scenarios and landslide spatial prediction models. Instead, in other cases like Vollein and Citrin, there is a shortage of products, with a brief internal technical report produced by the Aosta Valley regional authorities. In these cases, the total amount of information is limited with respect to the other case studies. In the Chervaz, Becca di Nona, and Bosmatto cases, the presence of different versions of the 
proposed geological model (Figure 3), which correspond to the evolution of the state of the art updated using new field data or geological/geophysical surveys results, is an important issue. These different interpretations (obtained in different times by different companies) could create a misunderstanding about the best model for the definition of scenarios and during emergencies. Instead, in the Vollein and Citrin cases, the mere presence of synthetic internal reports may limit a correct representation and characterization of the structure of the unstable area and their dynamic of deformations.

In all considered cases, the great work done by the regional authority is witnessed by the large amount of documents and reports draft during the years.

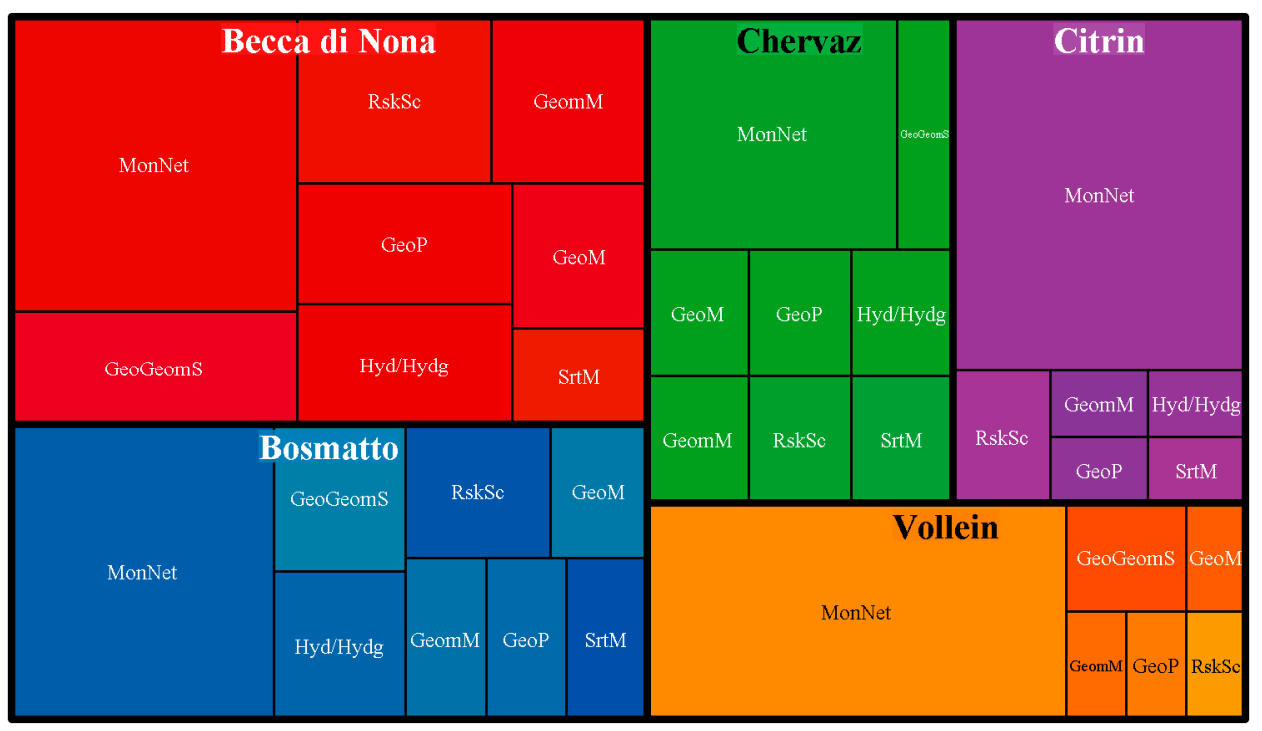

Figure 4. Three map chart shows the proportion of the eight original thematic variables recognized for each monitored landslide, highlighting which are the more frequent and which are eventually missing (Graph elaborated in R program).

The third section "Ground deformation time series", provides time series of collected monitoring measurements (Annex 1, Section 3). To produce such time series, we firstly pre-analyzed the raw data, handling missing values, noisy acquisitions, and by removing the outliers. Finally, specific smoothing functions were applied to the pre-elaborated datasets in order to obtain the adequate representation of landslide behavior. Figure 5 shows an example of elaborated data in the form of complete time series plots of Bosmatto landslide. The evolution of planimetric and altimetric displacement is presented. Additionally, an example of corresponding altimetric raw data is shown.

The choice of smoothing technique depends on features of raw data. For example, in the case of Bosmatto landslide, in order to preserve seasonal fluctuations, the moving average technique was applied to the raw datasets [51].

The generation of time series as a complete set provides a fast evaluation of landslide behavior over time. For example, eventual anomalies, seasonal patterns, reactivations and their magnitude can be easily localized with a long and complete time series. The organization of data provided in annual reports often limited the possibility to recognize seasonal or long-period trends. Another important point is that complete time series are fundamental instruments during the emergency conditions because can support the recognition of an anomalous evolution that can be a precursor of a collapse.

The last section "Synthesis and final proposal" of Bosmatto OM (Annex 1, Section 4) highlights the strengths and weaknesses of the actual state of knowledge. For the chosen case study, the main problem lies in the unclear definition of the landslide body. In fact, in the various technical reports more than one phenomenon is described, variably distinguishing the Bosmatto landslide s.s., located on the left side of the Letzebach river, and the Stadelte landslide, on the right side, in their turn divided into two portions, vegetated and non-vegetated. Those subdivisions became very clear only after eight 
years of technical studies and insights by more than one private agencies studies, passing through the identification of two old landslides to the designation of the Bosmatto and Stadelte landslides. This subdivision generates some difficulty also in the ground surface measurements presentation that sometimes are not clearly separated in the two landslide bodies. Therefore, among other suggestion, the Bosmatto OM recommended a noticeable separation of the Bosmatto and Stadelte cases, in order to provide a comprehensive overview of each one to be updated over time, also for the ground deformation time series elaboration. The reorganization of monitoring time series was important also to organize old records with the new subdivision of the monitored area in two landslides.
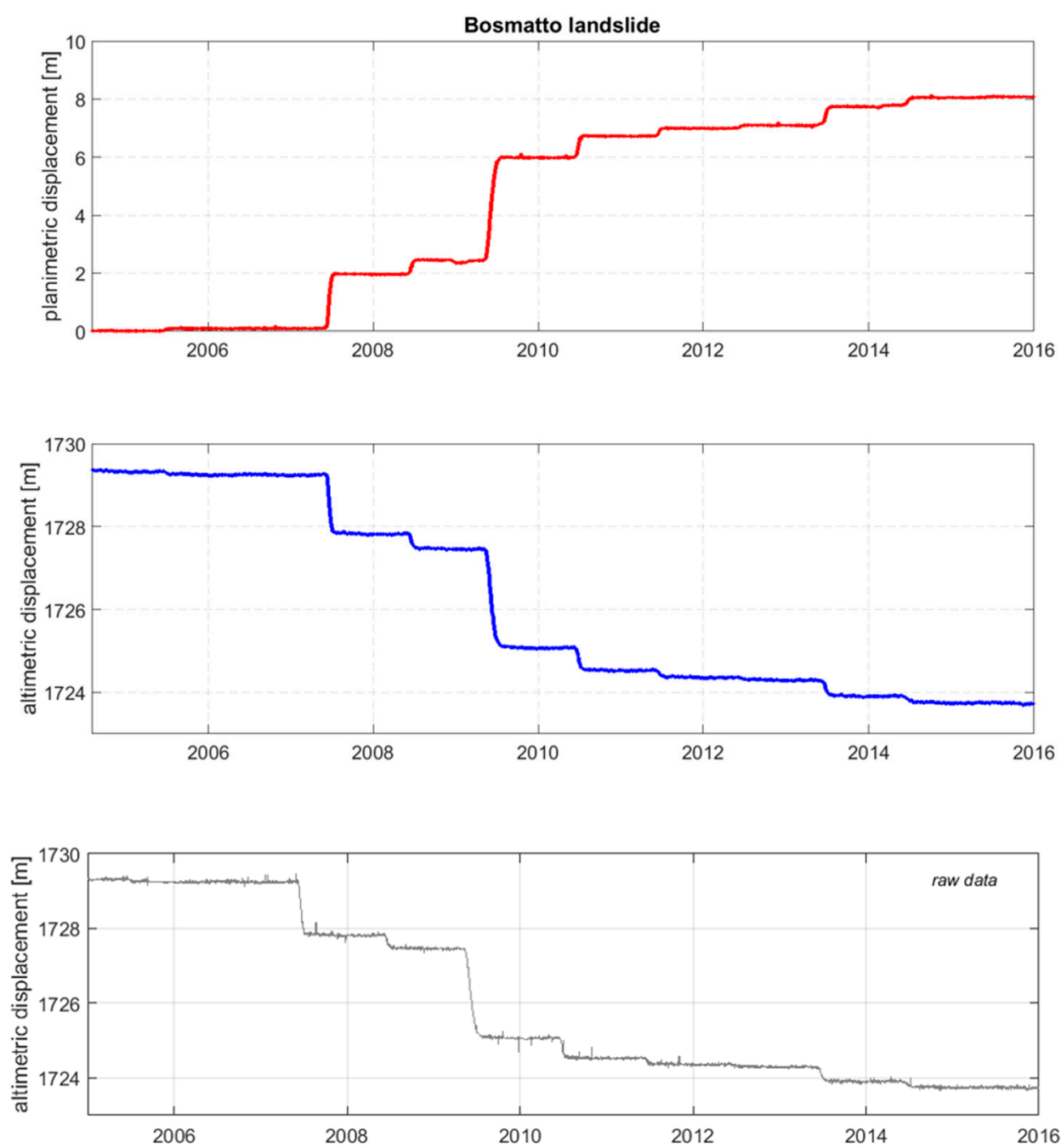

Figure 5. Bosmatto landslide elaborated time series of planimetric and altimetric displacement measured by global positioning system (GPS) for the entire monitored period. In the bottom, the raw dataset of altimetric displacement.

\section{Discussion}

In this paper, we want to analyze two underestimated topics in landslides studies: (i) The application of a usable science approach and (ii) the identification of a standard approach in data organization and management.

The concept of usable science, for the correct dissemination of scientific results, are sometimes considered a minor issue in landslide study and investigations. In particular during emergency, a proper dissemination of the available data about the observed landslide evolution can represent a key point for a good involvement of population, and an effective support to decision makers [24,26]. 
The scientific community usually focused on the improvement of methods and approaches for a more effective comprehension of landslide mechanism and for the identification, for example, of failure precursors [53]. However, it should be noted that, frequently, the main effort has been dedicated to the acquisition of valuable dataset of studied landslides. On the contrary, little importance are attributed to the way of mange available data, with the risk of using approaches not able to express the real capability of the available dataset. Commonly, scientific literature concerns on the application and implementation of WEB-GIS solutions for information and data management [22,25]. WEB-GIS are powerful solutions for the organization of information, but it is important to divide technical solutions aimed to display available data from more complex approach that are aimed to analyze and make a critical synthesis of these data.

Another important issue is the lack of a standard approach for landslide data collection. We analyzed the ICAO approach that can be considered one of the most standardized industrial sector. The safety of flights has been always considered one of the most important element for aviation, and the use of detailed standard approach represents one of the key element for the maintenance of high- safety levels. Starting from this example, we tried to transfer this approach in the organization of a pre-defined document that can be applied for the study of complex landslides. The high variability of landslides makes the possibility of the definition of a standard approach a critical challenge. According with our experience, we identified several macro-categories typically adopted for complex landslides analysis and description, representative for the structure of our standard document.

The OM is a site-specific document that collects all the available information of a studied landslide. It should be noted that, frequently, the monitoring data are performed and organized per year (e.g., a single report with monitoring results of many landslides in the same year). In addition, thematic studies often focus a single theme (e.g., geomorphological map or geotechnical characterization of a landslide). Instead, in our approach, all available information are re-organized in a single document referred to a single phenomenon.

The presented study attempted to provide the developed approach to five complex landslides studied and monitored for many years by the Aosta Valley Geological Survey. The considered case studies comprising active landslides that threaten urban areas, measured with near real time monitoring network.

The regional archive represents a case in point in the topic of large amount of data management. The archive is composed of numerous scientific and technical studies multi-sources, concerning diverse topics, repeated several time over a twenty year period, for each monitored landslide.

By the analysis of the results of the Aosta Valley monitoring network, we observed that there are some redundancies and contradictions in the considered case studies, mainly caused by the progressive availability of new investigation techniques during the years. In some cases, the acquisition of new data caused the elaboration of new geological models that could be in contradiction with the previous ones. It is worth noting that in many cases the development of contradictory models has been made possible by the lack, in the past, of direct investigations (e.g., core sampling boreholes) that could validate the geological interpretations.

The implementation of the OM allowed to an immediate access to the data and information relative to a specific phenomenon. The implemented method required the redaction of a standardized and iterative document, readily legible. The repeated structure, organized in specific sections, drops the reader to query the available data collected over the year about a single landslide or other phenomena. The OM do not want to be a mere catalogue, in which data are supplied in the extended version. Instead, the OM want to provide a reading guide of the available information, by providing a reasoned overview that highlights only the key elements relative to the analyzed phenomenon.

Jointly, the OM aimed to identify potential critical elements that are emerged from the analysis of all available material. It is important to point out that the OM has not a simply description of what are known about a landslide, but also a critical analysis of what we have to know. Thanks to 
this critical revision, it is possible to identify important missing information or weak points in the available dataset.

The presented standardized approach could also assure that future data will be organized with a compliant approach, limiting eventual mismatch or incorrect interpretation of previous studies. According to this purpose, the OM may represent a useful tool not only for policy-makers, but also for the scientific community, by providing reliable data, diverse technical and field information, and deformation measurements, able to describe a specific phenomenon and to define its behavior and evolution over time.

The activity undertaken with the implementation of the OMs give to the Geological Survey of the Aosta Valley Region a new and innovative method for a more standardized approach in landslide investigation and management of available data. The new document is scientifically validated by National Research Council that also made a periodical review of landslide monitoring data.

According to the results of this revision, the Geological Survey of the Aosta Valley Region plan the priority of maintenance activities of the monitoring network, and identify, for example, the need for a new geological model of some studied landslides. In the Bosmatto case, for instance, a core drilling campaign, allowing calibrating the previous geological hypotheses has been planned considering OM conclusions. Regional authorities plan also new boreholes with multi-parametric ground probes, in order to acquire in-depth data to re-evaluate the volume of monitored landslide.

This example shows how the definition of a review procedure and a correct management of available information can be used for the development of a "usable" document that can support decision makers for a better landslide hazard management. In addition, the codified procedure can also be considered a sort of audit process aimed to analyze the obtained results by the Geological Survey and suggest following inspections and analysis.

\section{Conclusions}

In this work, we considered the problem of the collection and organization of a large amount of information and data, relative to active complex and hazardous landslides. Usually, this is performed by the regional or national authorities, with the goal of ensuring safety of the managed territory and reducing landslide risk. Our purpose was to raise awareness of the potential hurdles that, often, these authorities have to deal with to build-up numerous technical and scientific reports and studies over time. In fact, this often leads to the creation of an extremely stratified and sometimes incoherent structure of available information. The availability of a large number of monitoring data and studies not quickly ready for use can reduce their effectiveness for the comprehension of landslide evolution and exacerbate the responsibilities of the technical staff and institutions, whose task is to administer a specific territory. This is therefore a serious issue, particularly during the emergency context. In this regard, the availability of not organized and not promptly accessible information can actually be a disadvantage element and not a benefit as it should be.

We proposed a solution based on the data analysis of the Aosta Valley region. We considered five large mass movements, which are monitored over many years. We had access to a large archive of different types of data, which were collected from one to two decades ago. In such conditions, a structured collection and a standardized organization of data appeared necessary. We generated an OM able to establish a synthesis of the landslide data in a standard format. An OM is a synthetic document that summarizes available information on a specific phenomenon. It also allows to identify missing elements and to verify existing ones. The OM facilitates the assessment of the state of knowledge, which is necessary step for a complete comprehension of each phenomenon. We recommended a periodical update of $\mathrm{OM}$, in order to obtain the maximum efficiency of this document.

The OM can also represent a fundamental tool during the emergency, where effective access to the available knowledge is fundamental for the identification of anomalous behavior that can be precursors of the collapse. 
By providing appropriate amendments, for example adding specific sections but also maintaining a standard structure, the OM could be easily applied in other contexts. For instance, in the case of a strategic infrastructure (e.g., pipeline), or a busy tourist path, the OM application could be a useful tool. By recognizing the potential critical sectors along the linear element, a single OM for each sector can be redacted, outlining the definition of the state of knowledge of each specific area, and defining with a specific focus the exposure and vulnerability of the element at risk, and delineating eventual mitigation strategies.

Supplementary Materials: The following are available online at http:/ /www.mdpi.com/2076-3263/8/12/485/s1, PDF S1: Bosmatto Operative Monography.

Author Contributions: M.C. and A.W. collected the data available on the five considered case studies; M.C. organized data and information and drafted the fine OMs; A.W. elaborated and analyzed the data of monitoring networks of the five case studies; D.G. supervised the project and implemented the OM structure; D.G. and D.B. revised the paper. All the authors contributed to paper writing and revision.

Funding: This research received no external funding.

Acknowledgments: The authors acknowledge Patrick Thuegaz of the Geological Service of the Aosta Valley region for providing assistance and help on consultation and accessibility of the regional data. The authors acknowledge Danilo Godone of the CNR IRPI of Turin for providing assistance and help on treemap graph generation in R environment.

Conflicts of Interest: The authors declare no conflict of interest. The funders had no role in the design of the study; in the collection, analyses, or interpretation of data; in the writing of the manuscript, or in the decision to publish the results.

\section{References}

1. Guha-Sapir, D.; Below, R.; Hoyois, P. EM-DAT: The CRED. OFDA International Disaster Database; Université Catholique de Louvain: Brussels, Belgium, 2016.

2. Herrera, G.; Mateos, R.M.; García-Davalillo, J.C.; Grandjean, G.; Poyiadji, E.; Maftei, R.; Filipciuc, T.-C.; Auflič, M.J.; Jež, J.; Podolszki, L.; et al. Landslide databases in the Geological Surveys of Europe. Landslides 2018, 15, 359-379. [CrossRef]

3. Corominas, J.; Moya, J.; Ledesma, A.; Lloret, A.; Gili, J.A. Prediction of ground displacements and velocities from groundwater level changes at the Vallcebre landslide (Eastern Pyrenees, Spain). Landslides 2005, 2, 83-96. [CrossRef]

4. Spizzichino, D.; Margottini, C.; Trigila, A.; Iadanza, C.; Linser, S. Landslide. In Mapping the Impacts of Natural Hazards and Technological Accidents in Europe; EEA Technical Report; European Environment Agency: København, Denmark, 2010; p. 140.

5. Ferlisi, S.; Cascini, L.; Corominas, J.; Matano, F. Rockfall risk assessment to persons travelling in vehicles along a road: the case study of the Amalfi coastal road (southern Italy). Nat Hazards 2012, 62, 691-721. [CrossRef]

6. Prise en Compte des Dangers Dus aux Mouvements de Terrain Dans le Cadre de L'aménagement du territoire (Consideration of Landslide Hazards in Land-use Practice). 1997. Available online: www.bwg.admin.ch/ themen/natur/f/index.htm (accessed on 8 October 2018).

7. Raetzo, H.; Lateltin, O.; Bollinger, D.; Tripet, J. Hazard Assessment in Switzerland-Codes of Practice for Mass Movements. Bull. Eng. Geol. Environ. 2002, 61, 263-268. [CrossRef]

8. Lateltin, O.; Haemmig, C.; Raetzo, H.; Bonnard, C. Landslide risk management in Switzerland. Landslides 2005, 2, 313-320. [CrossRef]

9. AGS. Guidelines for landslide susceptibility, hazard and risk zoning for land use planning. Aust. Geomech. 2007, 42, 13-36.

10. Dai, F.C.; Lee, C.F.; Ngai, Y.Y. Landslide risk assessment and management: an overview. Eng. Geol. 2002, 64, 65-87. [CrossRef]

11. Trigila, A.; Iadanza, C.; Spizzichino, D. IFFI Project (Italian landslide inventory) and risk assessment. In Proceedings of the First World Landslide Forum; UN/ISDR: Geneva, Switzerland, 2008; pp. 18-21.

12. Guzzetti, F. Landslide fatalities and the evaluation of landslide risk in Italy. Eng. Geol. 2000, 58, 89-107. [CrossRef] 
13. Remondo, J.; Bonachea, J.; Cendrero, A. Quantitative landslide risk assessment and mapping on the basis of recent occurrences. Geomorphology 2008, 94, 496-507. [CrossRef]

14. Mateos, R.M.; Herrera, G.; García-Davalillo, J.C.; Grandjean, G.; Poyiadji, E.; Maftei, R.; Filipciuc, T.-C.; Auflič, M.J.; Jez, J.; Podolszki, L.; et al. Integration of Geohazards into Urban and Land-Use Planning. Towards a Landslide Directive. The EuroGeoSurveys Questionnaire. In Workshop on World Landslide Forum; Springer: New York, NY, USA, 2017; pp. 1067-1072.

15. Poyiadji, E.; Kontogianni, V.; Nikolaou, N. Integration of Geohazards in Urban Planning and Management. Available online: https:/ / www.scientific.net/AEF.21.557 (accessed on 20 April 2018).

16. Amanti, M.; Bertolini, G.; Chiessi, V.; De Nardo, M.; Ramasco, M. Allegato 1-Guida Alla Compilazione Della Scheda Frane IFFI; Italian Geological Service publication: Rome, Italy, 2001.

17. Regione Piemonte SiFraP Sistema Informativo Frane in Piemonte. Available online: http://webgis. arpa.piemonte.it/geoportalserver_arpa/catalog/search/resource/details.page?uuid=ARLPA_TO: 07.04.02-D_2011-03-24-11:43 (accessed on 18 July 2018).

18. Assessorato Opere Pubbliche, Difese del Suolo e Edilizia Residenziale Pubblica, Protezione Civile Regionale-Centro Funzionale Regionale Catasto Dissesti. Available online: http:/ / catastodissesti.partout. it/ (accessed on 1 September 2015).

19. Regione Emilia-Romagna Carta Inventaio Frane e Archivio Storico Delle Frane. Available online: http:/ / ambiente.regione.emilia-romagna.it/geologia/cartografia/webgis-banchedati/cartografia-dissestoidrogeologico (accessed on 18 July 2018).

20. Rosi, A.; Tofani, V.; Tanteri, L.; Tacconi Stefanelli, C.; Agostini, A.; Catani, F.; Casagli, N. The new landslide inventory of Tuscany (Italy) updated with PS-InSAR: geomorphological features and landslide distribution. Landslides 2018, 15, 5-19. [CrossRef]

21. Guzzetti, F.; Cardinali, M.; Reichenbach, P. The AVI project: A bibliographical and archive inventory of landslides and floods in Italy. Environ. Manag. 1994, 18, 623-633. [CrossRef]

22. Calvello, M.; Pecoraro, G. FraneItalia: A catalog of recent Italian landslides. Geoenviron. Disasters 2018, 5, 13. [CrossRef]

23. Battistini, A.; Rosi, A.; Segoni, S.; Lagomarsino, D.; Catani, F.; Casagli, N. Validation of landslide hazard models using a semantic engine on online news. Appl. Geogr. 2017, 82, 59-65. [CrossRef]

24. Giordan, D.; Manconi, A.; Allasia, P.; Bertolo, D. Brief communication: On the rapid and efficient monitoring results dissemination in landslide emergency scenarios: the Mont de La Saxe case study. Nat. Hazards Earth Syst. Sci. 2015, 15, 2009-2017. [CrossRef]

25. Frigerio, S.; Schenato, L.; Bossi, G.; Cavalli, M.; Mantovani, M.; Marcato, G.; Pasuto, A. A web-based platform for automatic and continuous landslide monitoring: The Rotolon (Eastern Italian Alps) case study. Comput. Geosci. 2014, 63, 96-105. [CrossRef]

26. Wrzesniak, A.; Giordan, D. Development of an algorithm for automatic elaboration, representation and dissemination of landslide monitoring data. Geomat. Nat. Hazards Risk 2017, 8, 1898-1913. [CrossRef]

27. Moss, J.L. Using the Global Positioning System to monitor dynamic ground deformation networks on potentially active landslides. Int. J. Appl. Earth Obs. Geoinf. 2000, 2, 24-32. [CrossRef]

28. Squarzoni, C.; Delacourt, C.; Allemand, P. Differential single-frequency GPS monitoring of the La Valette landslide (French Alps). Eng. Geol. 2005, 79, 215-229. [CrossRef]

29. Giordan, D.; Allasia, P.; Manconi, A.; Baldo, M.; Santangelo, M.; Cardinali, M.; Corazza, A.; Albanese, V.; Lollino, G.; Guzzetti, F. Morphological and kinematic evolution of a large earthflow: The Montaguto landslide, southern Italy. Geomorphology 2013, 187, 61-79. [CrossRef]

30. Herrera, G.; López-Davalillo, J.C.G.; Fernández-Merodo, J.A.; Béjar-Pizarro, M.; Allasia, P.; Lollino, P.; Lollino, G.; Guzzetti, F.; Álvarez-Fernández, M.I.; Manconi, A.; et al. The differential slow moving dynamic of a complex landslide: Multi-sensor monitoring. In Workshop on World Landslide Forum; Springer: New York, NY, USA, 2017; pp. 219-225.

31. Antonello, G.; Casagli, N.; Farina, P.; Leva, D.; Nico, G.; Sieber, A.J.; Tarchi, D. Ground-based SAR interferometry for monitoring mass movements. Landslides 2004, 1, 21-28. [CrossRef]

32. Squarzoni, C.; Delacourt, C.; Allemand, P. Nine years of spatial and temporal evolution of the La Valette landslide observed by SAR interferometry. Eng. Geol. 2003, 68, 53-66. [CrossRef]

33. Van Westen, C. Geo-information tools for landslide risk assessment: An overview of recent developments. In Landslides: Evaluation and Stabilization; Taylor\& Francis Group: London, UK, 2004; pp. 39-56. 
34. Tofani, V.; Segoni, S.; Agostini, A.; Catani, F.; Casagli, N. Technical Note: Use of remote sensing for landslide studies in Europe. Nat. Hazards Earth Syst. Sci. 2013, 13, 299-309. [CrossRef]

35. Baldo, M.; Bicocchi, C.; Chiocchini, U.; Giordan, D.; Lollino, G. LiDAR monitoring of mass wasting processes: The Radicofani landslide, Province of Siena, Central Italy. Geomorphology 2009, 105, 193-201. [CrossRef]

36. Crosta, G.B.; Lollino, G.; Paolo, F.; Giordan, D.; Andrea, T.; Carlo, R.; Davide, B. Rockslide monitoring through multi-temporal LiDAR DEM and TLS data analysis. In Engineering Geology for Society and Territory; Springer: New York, NY, USA, 2015; Volume 2, pp. 613-617.

37. Mittal, S.; Singh, M.; Kapur, P.; Sharma, B.; Shamshi, M. Design and development of instrumentation network for landslide monitoring and issue an early warning. J. Sci. Ind. Res. 2008, 67, 361.

38. Garcia, C.; Fearnley, C.J. Evaluating critical links in early warning systems for natural hazards. Environ. Hazard. 2012, 11, 123-137. [CrossRef]

39. Vogel, C. Usable Science: An Assessment of Long-Term Seasonal Forecasts Amongst Farmers in Rural Areas of Sourth Africa. S. Afr. Geogr. J. 2000, 82, 107-116. [CrossRef]

40. Dilling, L.; Lemos, M.C. Creating usable science: Opportunities and constraints for climate knowledge use and their implications for science policy. Glob. Environ. Chang. 2011, 21, 680-689. [CrossRef]

41. Tang, S.; Dessai, S. Usable Science? The U.K. Climate Projections 2009 and Decision Support for Adaptation Planning. Weather Clim. Soc. 2012, 4, 300-313. [CrossRef]

42. Cash, D.W.; Clark, W.C.; Alcock, F.; Dickson, N.M.; Eckley, N.; Guston, D.H.; Jäger, J.; Mitchell, R.B. Knowledge systems for sustainable development. Proc. Natl. Acad. Sci. USA 2003, 100, 8086-8091. [CrossRef]

43. Dal Piaz, G.V.; Bistacchi, A.; Massironi, M. Geological outline of the Alps. Episodes 2003, 26, 175-180.

44. De Giusti, F.; Dal Piaz, G.; Massironi, M.; Schiavo, A. Carta geotettonica della Valle d'Aosta. Memorie di Scienze Geologiche 2003, 55, 129-149.

45. Bistacchi, A.; Piaz, G.D.; Massironi, M.; Zattin, M.; Balestrieri, M. The Aosta-Ranzola extensional fault system and Oligocene-Present evolution of the Austroalpine-Penninic wedge in the northwestern Alps. Int. J. Earth Sci. 2001, 90, 654-667. [CrossRef]

46. Giardino, M.; Giordan, D.; Ambrogio, S. GIS technologies for data collection, management and visualization of large slope instabilities: Two applications in the Western Italian Alps. Nat. Hazards Earth Syst. Sci. 2004, 4, 197-211. [CrossRef]

47. Ratto, S.; Bonetto, F.; Comoglio, C. The October 2000 flooding in Valle d'Aosta (Italy): Event description and land planning measures for the risk mitigation. Int. J. River Basin Manag. 2003, 1, 105-116. [CrossRef]

48. ISPRA Ambiente IFFI Catalogue. Available online: http://www.isprambiente.gov.it/it/progetti/suolo-eterritorio-1/iffi-inventario-dei-fenomeni-franosi-in-italia (accessed on 1 September 2015).

49. Martinotti, G.; Giordan, D.; Giardino, M.; Ratto, S. Controlling factors for deep-seated gravitational slope deformation (DSGSD) in the Aosta Valley (NW Alps, Italy). Geol. Soc. Lond. Spec. Publ. 2011, 351, 113-131. [CrossRef]

50. Lovisolo, M.; Ghirotto, S.; Scardia, G.; Battaglio, M. The use of Differential Monitoring Stability (DMS) for remote monitoring of excavation and landslide movements. In Proceedings of the Sixth International Symposium on Field Measurements in Geomechanics, Oslo, Norway, 15-18 September 2003; pp. 519-524.

51. MATLAB. Version 9.2.0 (R2017a); The MathWorks Inc.: Natick, MA, USA, 2017.

52. Giardino, M.; Ratto, S.; Palomba, M.; Alberto, W.; Armand, M.; Cignetti, M. The Debris Flows Inventory of the Aosta Valley Region: An Integrated Natural Hazards Assessment. In Landslide Science and Practice; Springer: Berlin, Germany, 2013; pp. 127-134. ISBN 978-3-642-31324-0.

53. Manconi, A.; Giordan, D. Landslide failure forecast in near-real-time. Geomat. Nat. Hazards Risk 2016, 7, 639-648. [CrossRef]

(C) 2018 by the authors. Licensee MDPI, Basel, Switzerland. This article is an open access article distributed under the terms and conditions of the Creative Commons Attribution (CC BY) license (http:/ / creativecommons.org/licenses/by/4.0/). 